\title{
Analysis of Temperature Field of High Speed Gear Box Based on ANSYS Workbench
}

\author{
WEI Ling hui ${ }^{\mathrm{a}}, \mathrm{XU}$ Hong hai \\ North China University of Technology, Beijing 100144 , China \\ Weilinghui@126.com
}

\begin{abstract}
Key words: reducer; speed; temperature field; finite element method
Abstract: Using the computational fluid dynamics, heat transfer theory and mechanics theory to analyze the internal heat source types and heat transfer path of high speed gear box, and establishing the steady-state heat transfer model. Based on the finite element theory, the finite element model of fluid solid coupling is analyzed, the distribution of temperature field for the gear box is obtained, and the key part of the distribution of temperature field is determined. Through simulation results of the finite element, the basis for the prediction and reliable operation for the gear box of high speed can be provided by the analysis model of fluid solid coupling.
\end{abstract}

\section{Introduction}

High speed drive gear box is an important device for power transfer and movement, and responsible for delivering the power of device to the execution part, and has an important influence on the equipment safety, dynamic performance and power transmission. Because of the higher speed and increasing heat loss of the transmission system of the high speed gear box, there are many problems faced on every part of the lubricating surface. Taking a certain type of high speed gear box as the research object, conducting simulation analysis for heat transfer model of heat flow coupling, the change law of the relevant physical quantities is analyzed by means of the working process of the gear box. The reference basis for the balance temperature, temperature distribution of key parts and temperature forecast and research structure of the new operating conditions can be provided with the help of finding out the heat balance of the gear box.

\section{Analysis of heat balance process and heat source for gear box}

Heat source calculation is the basis of the research on temperature field of the gear box. The heat generated during the transmission of high speed gear box is mainly derived from the power loss of various kinds of friction pairs which mainly include the power loss of bearing friction, oil film viscous friction between lubricating oil layer and sliding, and rolling friction between two meshing tooth .

The transmission of heat in the gear box is: heat source generated can be transmitted to the parts of gear surface, internal gear and transmission shaft, and the temperature field was built. Eventually the heat is transferred to the gear box, and is sent out through the form of forced convection. The heat of the oil and gas mixture formed by the lubricating oil and air is circulated through the box body to the outside air in the form of heat convection. To ignore the radiation heat transfer between the various parts of the body, the heat is continuously passed to the outside air, and ultimately achieve dynamic balance. The heat transfer route can be expressed in Figure 1.

\section{Heat source of gear box calculation}

Heat power of each heat source is calculated according to heat source analysis of the gear box. The distribution of heat source is shown in figure 2. 


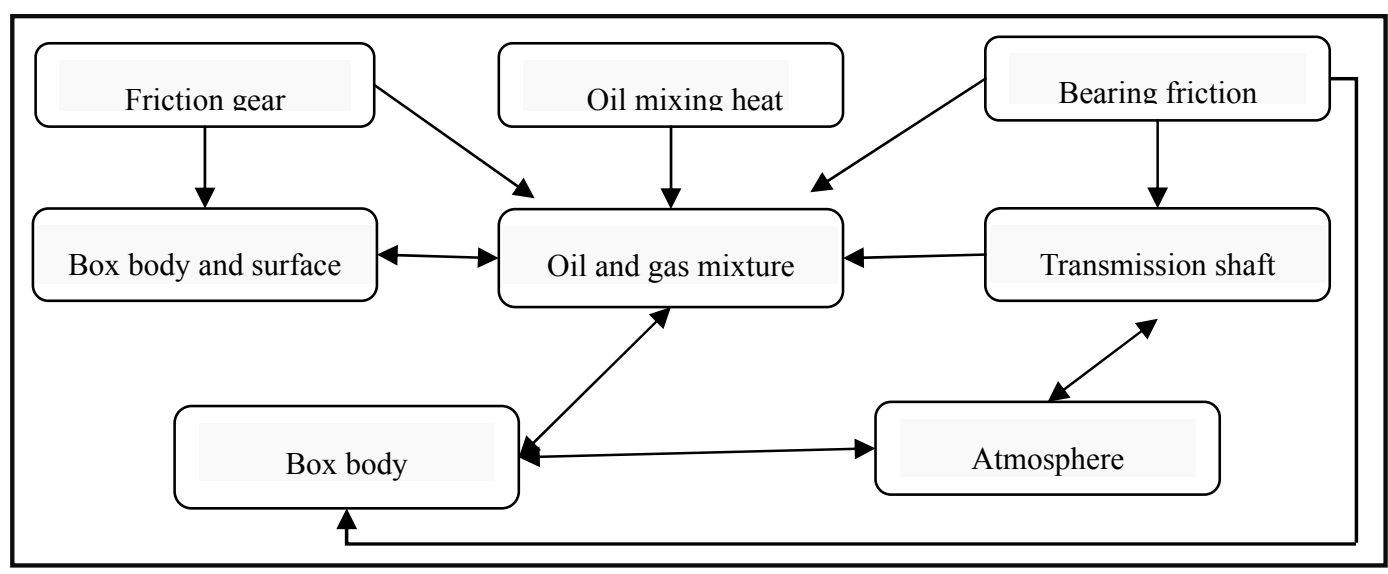

Fig. 1 Route of heat transmission

Working condition is set as follow: clockwise, the running speed is $300 \mathrm{~km} / \mathrm{h}$, the quantity of oil injection is $6 \mathrm{~L}$, the wind speed is $5 \mathrm{~m} / \mathrm{s}$, the ambient temperature is $27^{\circ}$.

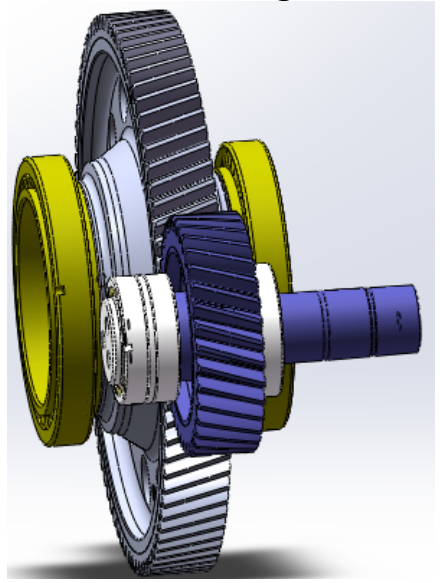

Fig. 2 The distribution of heat source

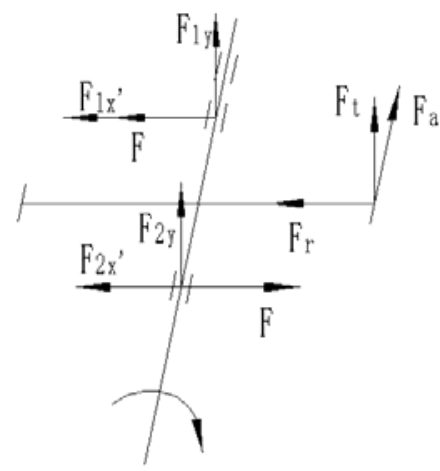

Fig. 3 diagram of the bearing force

(1) Bearing heating power calculation

The maximum output power of the motor is $615 \mathrm{kw}$, and the basic parameters of gear is shown in Table 1.

Table 1 the basic parameters ofgear

\begin{tabular}{|c|c|c|c|}
\hline Gear parameters & Symbol & $\begin{array}{l}\text { Active } \\
\text { gear(small) }\end{array}$ & Driven gear(large) \\
\hline Normal modulus & $\mathrm{m}_{\mathrm{n}}$ & \multicolumn{2}{|c|}{6} \\
\hline Teeth number & $\mathrm{Z}$ & 35 & 85 \\
\hline Transmission ratio & $\mathrm{i}$ & \multicolumn{2}{|c|}{$20^{\circ}$} \\
\hline Pressure angle & $\mathrm{a}_{\mathrm{n}}$ & \multicolumn{3}{|c|}{$18^{\circ}$} \\
\hline Helix angle & $\beta$ & 69 & 65 \\
\hline teeth width & $\mathrm{b}$ & 690 \\
\hline Gear center distance & $\mathrm{a}^{*}$ & \multicolumn{3}{|c|}{$2.4 \times 10^{5} \mathrm{~km}$} \\
\hline Tooth top circle diameter & $\mathrm{da}$ & 236.277 & 536.753 \\
\hline Gear design service life & & \multicolumn{3}{|c|}{2.46} \\
\hline Indexing circle diameter & $\mathrm{d}$ & 220.807 & 520.332 \\
\hline root circle diameter & $\mathrm{df}$ & 207.307 & \multicolumn{3}{|c|}{} \\
\hline
\end{tabular}

1) input shaft bearing capacity calculation

$\mathrm{T}=9550 \times \frac{\mathrm{P}}{\mathrm{n}}, \mathrm{n}_{1}=\mathrm{v} / 2 \pi \mathrm{r}, \mathrm{n}_{2}=\mathrm{i} \times \mathrm{n}_{1}$.

Obtained motor torque transmission $\mathrm{T}$, and circumferential force. Gear is $\mathrm{F}_{\mathrm{t}}=2000 * \mathrm{~T} / \mathrm{d}$.

Radial force $F_{r}=F_{t} * \tan \alpha_{n} / \cos (\beta)$.

Axial force $\mathrm{F}_{\mathrm{a}}=\mathrm{F}_{\mathrm{t}} * \tan (\beta)$. 
According to the distribution of heat source on the shaft, the torque of the gear is generated by the axial force, and $\mathrm{F}$ is generated by the torque acting on the bearing.

$$
\begin{gathered}
F=F_{a} \cdot r / a=3588.0 \mathrm{~N}, \quad F_{1 x}{ }^{\prime}=F_{r} a_{2} / a=1787.6 \mathrm{~N}, \quad F_{2 x}{ }^{\prime}=F_{r} a_{1} / a=2580.0 \mathrm{~N} \\
F_{1 y}=F_{t} a_{2} / a=4671.1 \mathrm{~N}, \quad F_{2 y}=F_{t} a_{1} / a=6741.6 \mathrm{~N}, \quad F_{1 x}=F_{1 x}{ }^{\prime}+F=5375.6 \mathrm{~N} \\
F_{2 x}=F_{2 x}{ }^{\prime}-F=-1008.0 \mathrm{~N}, \quad F_{1}=\sqrt{F_{1 x}{ }^{2}+F_{1 y}{ }^{2}}=7121.5 \mathrm{~N} \\
F_{2}=\sqrt{{F_{2 x}}^{2}+F_{2 y}{ }^{2}}=6816.5 \mathrm{~N}, \quad F_{5}=F_{a}=3708.2 \mathrm{~N}
\end{gathered}
$$

Similarly the output shaft bearing force can be calculated, Bearing 3, 4 of the force is

$$
\left\{\begin{array} { c } 
{ F _ { 3 } = 7 6 3 3 . 5 N } \\
{ F _ { 3 z } = 0 }
\end{array} \quad \left\{\begin{array}{l}
F_{4}=11028.8 N \\
F_{4 z}=3708.2 N
\end{array}\right.\right.
$$

2) Heating power of each bearing

$\mathrm{P}$ is equivalent dynamic load of bearing. $\mathrm{M}$ is Friction torque of bearing and $\mathrm{Q}$ is calorific value of bearing.

$P_{1}=1.2 F_{1}=8545.8 \mathrm{~N}, M_{1}=0.5 \mu P_{1} d_{1}=961.4 \mathrm{Nmm}, Q_{1}=1.05 \times 10^{-4} M_{1} n_{1}=470.4 \mathrm{~W}$.

The calorific value of the bearing is shown in Table 2 .

Table 2 Calorific value of bearing

\begin{tabular}{c|c|c|c|c|c}
\hline Position & Bear1 & Bear2 & Bear3 & Bear4 & Bear5 \\
\hline Calorific value & $470.4 \mathrm{~W}$ & $450.2 \mathrm{~W}$ & $369 \mathrm{~W}$ & $491.2 \mathrm{~W}$ & $81.7 \mathrm{~W}$ \\
\hline
\end{tabular}

$3 \longdiv { \text { Heating power of oil mixing calculation } }$

Heating power calculation of the loss of oil mixing $Q_{6}=347.5 \mathrm{bhv} v^{1.5}$.

b-Large gear width $(0.0645 \mathrm{~m})$.

$\mathrm{v}$-Large gear pitch circle line speed $(53.8 \mathrm{~m} / \mathrm{s})$.

h-Gear oil height $(0.053 \mathrm{~m})$.

The result of Calculation $Q_{6}=468.8 \mathrm{~W}$.

4) Mesh calculation of heating power

$Q_{7}=Q-Q_{1}-Q_{2}-Q_{3}-Q_{4}-Q_{5}-Q_{6}$

$Q_{7}$ - Gear meshing heating power.

$Q$-Total heating power of gear box, efficiency of gear box is 0.99 , input power is $615 \mathrm{KW}$.

The calculation result is $468.8 \mathrm{~W}$

5) Calculation of Convective heat transfer coefficient for box wall.

(a) Calculation of convective heat transfer coefficient for box inner wall.

$N u=0.664 \operatorname{Re}^{\frac{1}{2}} \operatorname{Pr}^{\frac{1}{3}}$.

$\mathrm{Nu}$-Plate average heat transfer coefficient.

Re-Reynolds coefficient.

Pr-Prandtl constant

and, $\operatorname{Re}=u L / v$

$\mathrm{u}$-Lubricating oil flow rate

L-Wall characteristic length

$\mathrm{v}$-Kinematic viscosity

In summary, the convection coefficient of heat transfer between fluid and inner wall of the gear box is $h_{1}=\lambda N u / L$.

(b) Calculation of total heat transfer coefficient of gear box.

According to the empirical formula: $K=24.6+3.3 \sqrt{V}$. 
Vehicle driving speed.

(c)The coefficient calculation of convection heat transfer in external box wall

$$
K=\frac{1}{\frac{1}{h_{1}}+\frac{\delta}{\lambda}+\frac{1}{h_{2}}}
$$

$\delta$-thickness of gear box wall

$\lambda$-heat conduction coefficient of box

$\mathrm{h}_{2}$-Heat transfer coefficient of box external wall

The calculated result from above $\mathrm{h}_{2}=52 \mathrm{~W} /\left(\mathrm{m}^{2} \cdot \mathrm{k}\right)$

\section{Establishment of simplified calculation model}

The model was simplified in SolidWorks. The fillet, chamfer, bolts and other important structures and parts was removed in order to ensure the accuracy of results, the model was maintained as far as possible as required, The simplified 3D model was filled with the DM workbench module, and grid division was completed in workbench of meshing module. The totality grid model was gotten as shown in Figure 4.

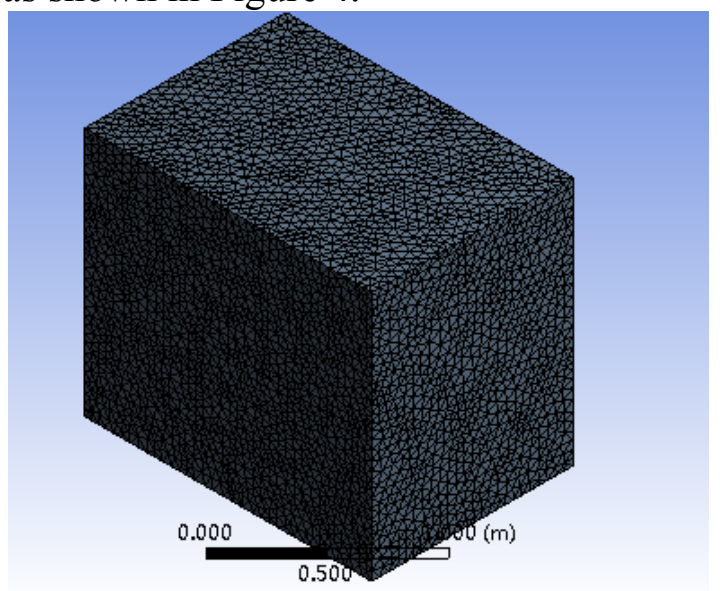

Fig. 4 Totality grid model

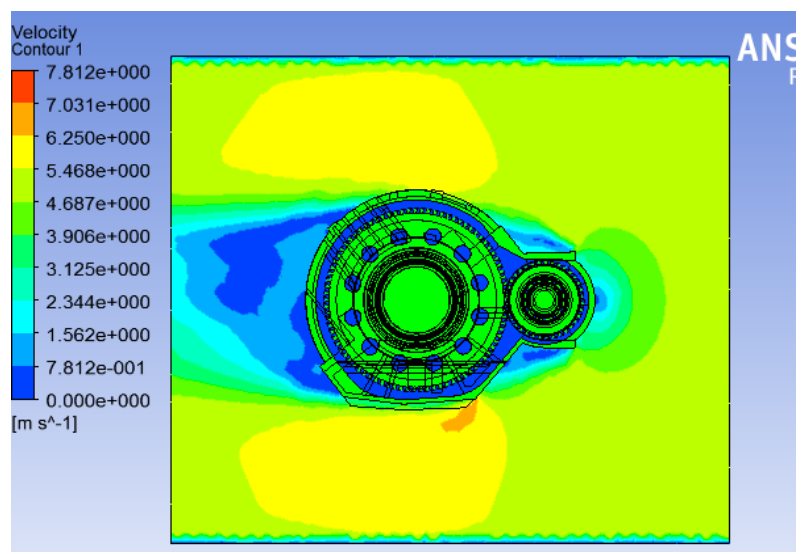

Fig. 5 nephogram of velocity

\section{Results of simulation analysis}

The nephogram of velocity field is as shown in figure 5.In this nephogram, inlet velocity is $5 \mathrm{~m} / \mathrm{s}$, top speed is $7.812 \mathrm{~m} / \mathrm{s}$, and the case is happened in sharp change area of the shape of the box.

The situation of steady-state temperature field of box wall is as shown in Figure 6 to 9.
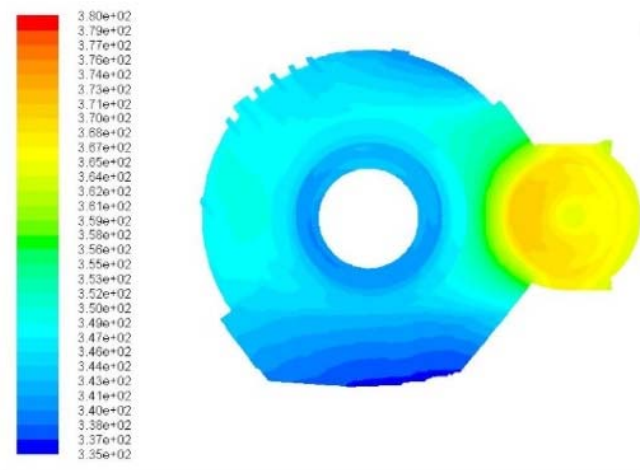

Contours of Static Temperature is ANSYS Fluent 15.0 (3d, dp. ptons, ske)

Fig. 6 nephogram of A surface temperature field

The highest temperature pinion of A surface happened on the external surface of box which focused on the pinion bearing and the gear wheel side bias. The highest temperature is $372 \mathrm{k}$, i.e. 99 
C.

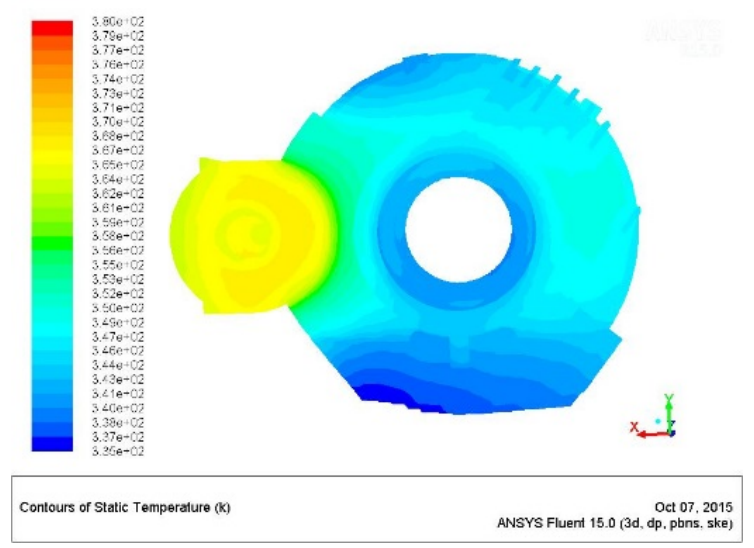

Fig. 8 nephogram of B surface temperature field

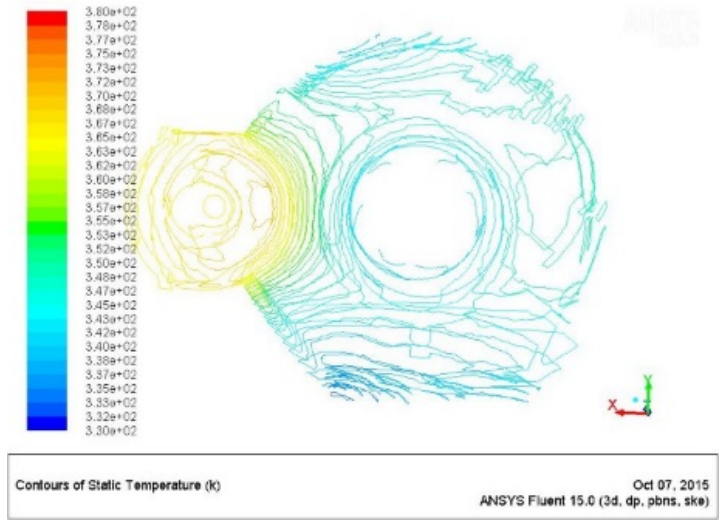

Fig. 9 contour map of B Surface Table 3 Condition 1 temperature situation table

\begin{tabular}{ccc}
\hline Site name & $\mathrm{T}_{\mathrm{MAX}}\left({ }^{\circ} \mathrm{C}\right)$ & Temperature maximum part \\
\hline Box A surface & $99{ }^{\circ} \mathrm{C}$ & $\begin{array}{c}\text { the external surface of box which focused on the } \\
\text { pinion bearing and the gear wheel side bias } \\
\text { the external surface of box which focused on the } \\
\text { pinion bearing and the gear wheel side bias }\end{array}$ \\
\hline
\end{tabular}

\section{Conclusion}

In this paper, the heat source and heat transfer process was analyzed, the heat transfer model of the transmission gear box was built, and losses of various thermal power of gear box were analyzed and calculated according to the actual use of the high speed transmission gear box. The temperature field of the gear box is analyzed to find out the different position of the highest balance temperature of the gear box. The analysis process can provide reference basis for the forecast of temperature distribution of the high speed gear box and the temperature distribution of the key parts and so on.

\section{Acknowledgements}

Project Number:KM201510009003

\section{Reference}

[1] HUO Xiao-qiang,MA Biao,LIU Hua-lin. Study on heat load performance of cases in comprehensive drive transmissions[J].Construction Machinery and Equip-ment,2005(2):27 -29.

[2] Long H,Lord A A,Gethin D T,et al. Operating temperatures of oil-lubricated medium-speed gears: numerical models and experimental results[J].Jour-nal of Aerospace Engineering,2003,21(2):87 -106.

[3] Combet F,Gelman L.Novel Adaptation of the Demodulation Technology for Gear Detection to Variable Amplitudes of Mesh Harmonics[J].Mechanical Systems and Signal Perocessing,2011,25(3):839-845.

[4] LIU Kai,LI Xu-hong,LI Yan-ping. Temperature F field Calculation for Heavy-Duty Reducer[J]. Journal of Xi an University of Technology(2000)Vol 16No 3:221-225. 